\title{
Characterization of human infiltrating and circulating gamma-delta T cells in prostate cancer
}

\author{
Marco Vella ${ }^{1}$, Daniela Coniglio ${ }^{2}$, Alberto Abrate ${ }^{1}$, Cristina Scalici Gesolfo ${ }^{1}$, Elena Lo Presti ${ }^{2}$, Serena Meraviglia ${ }^{2}$, \\ Vincenzo Serretta ${ }^{1}$, Alchiede Simonato ${ }^{1}$ \\ ${ }^{1}$ Department of Surgical Oncological and Oral Sciences, Section of Urology, University of Palermo, Palermo, ${ }^{2}$ Department of Biopathology and Clinical and Forensic \\ Biotechnology, University of Palermo, Palermo, Italy
}

Purpose: The aim of our study was to prospectively evaluate the distribution of gamma-delta $(\gamma \delta) 1$ and $\gamma \delta 2 \mathrm{~T}$ cells and their phenotypes in peripheral blood and prostate samples of patients diagnosed with or without prostate cancer (PCa) at prostate biopsy. Materials and Methods: A consecutive series of 43 outpatients underwent trans-rectal echo-guided prostate biopsy for suspected PCa. Flow cytometry analysis was used to identify and characterize the $\gamma \delta$ T cells populations in peripheral blood and tissue samples. Patients were stratified according to the presence or not of PCa, and its International Society of Urological Pathology (ISUP) grade (1 vs. $\geq 2$ ).

Results: The distribution of $\gamma \delta$ T cells in peripheral blood and prostate tissue showed wide variability and non-significant differences. A slightly higher percentage of $\delta 2 \mathrm{~T}$ cells and a slightly lower percentage of $\delta 1 \mathrm{~T}$ cells were found in peripheral blood of cancer patients. A non-significantly higher percentage of both $V \delta 1$ and $V \delta 2$ was expressed in cancer tissues, but a trend for lower distribution of $\delta 1$ and $\delta 2 \mathrm{~T}$ cells was observed in ISUP grade $\geq 2$. The "central memory" and "effector memory" were the most expressed $T$ cells phenotype in peripheral blood and tissue samples. However no substantial differences in T cells subtypes distribution between cancer and healthy tissue were observed.

Conclusions: No substantially different percentages of $\gamma \delta T$ cells were found in peripheral blood and biopsy samples of healthy and PCa patients. However a non-significant trend for lower infiltrate in higher ISUP grade cancer tissue was observed, suggesting a possible role for the immunosurveillance of $\mathrm{PCa}$.

Keywords: Biopsy; Immunologic surveillance; Neoplasm grading; Prostatic neoplasms; T-Lymphocyte subsets

This is an Open Access article distributed under the terms of the Creative Commons Attribution Non-Commercial License (http://creativecommons.org/licenses/by-nc/4.0) which permits unrestricted non-commercial use, distribution, and reproduction in any medium, provided the original work is properly cited.

\section{INTRODUCTION}

Prostate cancer $(\mathrm{PCa})$ is the most common malignant neoplasm in male patients. $\mathrm{PCa}$ is a heterogeneous tumor with potentially long natural and clinical history, reflected in its common finding during autopsies carried out for other causes of death. In fact, many PCa are not expected to have clinically significant progression [1,2]

There is good evidence that cancer can naturally be controlled by the immune system. Mononuclear cells often infiltrate tumoral tissues and their presence were found to improve prognosis in patients with several tumors [3].

Received: 21 September, 2018 - Accepted: 3 February, 2019

Corresponding Author: Marco Vella

Department of Surgical Oncological and Oral Sciences, Section of Urology, University of Palermo, via del Vespro 129, 90127 Palermo, Italy

TEL: +39-338-2900616, FAX: +39-091-655-2417, E-mail: marco.vella@unipa.it

ORCID: https://orcid.org/0000-0003-0924-5111 
Gamma-delta $(\gamma \delta) \mathrm{T}$ lymphocytes are effector cells that may play a critical role in cancer immunosurveillance and recent clinical trials support their use as immunotherapic agents, either via the adoptive transfer of ex vivo expanded $\gamma \delta \mathrm{T}$ cells or following the activation of $\gamma \delta \mathrm{T}$ cells in vivo by compounds such as phosphoantigens or aminobisphosphonates [4]

Three main populations of $\gamma \delta \mathrm{T}$ cells are recognizable on the basis of $\delta$ chain expression, phenotypic and functional parameters. In fact the functional responses of $\gamma \delta \mathrm{T}$ cells can be stratified by the $\mathrm{V}$ region of the $\gamma \delta \mathrm{T}$ cell receptor (TCR). The $\gamma \delta \mathrm{T}$ cells expressing the V $\delta 1$ TCR chain are mostly found in epithelial and mucosal tissues, contrasting tissutal damage, infection or transformation. Conversely, the $\gamma \delta \mathrm{T}$ cells expressing the V $\delta 2$ TCR chain are the most common circulating $\gamma \delta \mathrm{T}$ lymphocytes [5] and can also act as antigenpresenting cells [6,7], activating $\mathrm{CD} 4^{+} \mathrm{T}$ cells. Finally the V83 $\mathrm{T}$ cells, represent only the $0.2 \%$ of the circulating $\mathrm{T}$ cells [8].

V $\delta 1 \mathrm{~T}$ cells primarily reside within epithelial tissues (therefore also in the prostate) as first line agents of immunosurveillance, binding major histocompatibility complex (MHC) Class I-related ligands [9], that may act as tumor associated antigens. On the contrary more than the $90 \%$ of the circulating $\gamma \delta \mathrm{T}$ cells express the V $\delta 2$ receptor [10]. The $\mathrm{V} \gamma 9 \mathrm{~V} \delta 2$ displays a broad reactivity against stressmediated metabolites produced by both microbial agents and tumors.

Moreover, $\gamma \delta \mathrm{T}$ lymphocytes can be categorized for their different surface marker expression and effector functions as naive (Thaive), central memory (Tcm), effector memory (Tem) and terminally differentiated (Temra) cells [11]. The $\gamma \delta$ $\mathrm{T}$ cells development is not always completed in the thymus, as many of them migrate to the peripheral tissues from the bone marrow with immediate effector function [12]. While Tnaive and Tcm cells home to lymph nodes without immediate effector functions, Tem and Temra cells instead migrate to inflammation sites, displaying immediate effector functions [11].

Considering $\mathrm{PCa}$ as a model for the antitumor properties of local V $\delta 1 \mathrm{~T}$ and migrated V $\delta 2 \mathrm{~T}$ cells, the aim of this study was to prospectively evaluate the frequency, the phenotype and the effector function of $\gamma \delta 1$ and $\gamma \delta 2 \mathrm{~T}$ cells in prostate biopsy specimens and peripheral blood samples according to the diagnosis of $\mathrm{PCa}$ (vs. healthy patients) and its International Society of Urological Pathology (ISUP) grade.

\section{MATERIALS AND METHODS}

A consecutive series of 43 outpatients who underwent trans-rectal echo-guided prostate biopsy for suspicious PCa were enrolled. A standard 12 core sextant biopsy of the peripheral zone was performed using a $16 \mathrm{G}$ needle. The aim of the study was to assess the effect of the presence of $\mathrm{PCa}$ and its ISUP grade on the distribution of $\gamma \delta \mathrm{T}$ cells in prostate biopsy specimens and peripheral blood samples. For the aim of the study two additional cores (one left and one right) from the marginal zone of the prostate gland and a peripheral blood sample were taken from each patient. A written informed consent to participate was obtained from all the patients involved. According to Italian rules (art. 13, DLgs n. 196/03), this study did not require authorisation by the local ethical committee [13].

\section{Isolation and FACS analysis of tumor-infiltrat- ing lymphocytes and peripheral blood mono- nuclear cells}

For tumor-infiltrating lymphocytes (TILs) analysis, the sample tissue of the two additional cores was obtained fresh and immediately transported to the laboratory in sterile saline solution for processing. Tissue was first minced into small pieces and digested with collagenase type IV, hyaluronidase and DNAase (Sigma, St. Louis, MO, USA) for one hour at $37^{\circ} \mathrm{C}$. After digestion, the cells extracted were washed twice in RPMI 1640 medium.

Whole blood samples obtained from the same patients have been used for the comparative analysis between immunological status in peripheral blood and in the tumor or healthy tissue. The peripheral blood mononuclear cells (PBMCs) were separated from whole blood by density gradient centrifugation using Ficoll-Hypaque (Pharmacia Biotech, Uppsala, Sweden). Cells viability was checked by Trypan blue assay at microscopy.

TILs and PBMCs were stained with the same monoclonal antibodies (mAbs), acquired and analyzed by flow cytometry on FACSCalibur and FACS CANTO II. The entire $\gamma \delta \mathrm{T}$ cell population was characterized using anti-CD3 peridinin chlorophyll protein (PerCp), anti-V $\delta 1$ fluorescein isothiocyanate (FITC), anti-V82 phycoerythrin (PE)-, antiCD27 allophycocyanin (APC)- and anti-CD45RA PE-Cy7conjugated mAbs (BD Biosciences, Mountain View, CA, USA). On the basis of surface marker expression, we distinguished CD45RA ${ }^{+} \mathrm{CD} 27^{+}$Tnaive, CD45RACD27 ${ }^{+} \mathrm{Tcm}$, CD45RACD27 Tem, CD45RA ${ }^{+}$CD27 Temra cells, according to previously published methods [11]. Considering the high specificity of the markers used, no unspecific autofluorescent 
or compensation background was assessed.

The gating strategy consisted in the progressive measurement of total lymphocytes and specific cell types (Fig. 1). For every sample 100,000 nucleated cells were acquired and values were expressed as percentage of viable lymphocytes.

\section{Statistical analysis}

Patients were stratified according to the presence or not of PCa at sextant biopsy; the cancer patients were then substratified according to the ISUP grade ( 1 vs. $\geq 2$ ). Healthy patients were considered those with normal histological findings or benign prostatic hyperplasia (BPH). The means of continuous variables and the distribution of nominal variables were compared with Student's t-test and Pearson's chi-squared test, respectively. All statistical analyses were performed using MedCalc v12.0 (MedCalc Software bvba, Ostend, Belgium) and GraphPad Prism v7.0 (GraphPad Software Inc., La Jolla, CA, USA). A p-value $<0.05$ was considered statistically significant.

\section{RESULTS}

Overall, 43 patients were enrolled. After prostate biopsy 21 patients were diagnosed with cancer, 18 patients without cancer (healthy: normal or BPH) and 4 patients had prostatic intraepithelial neoplasia (PIN). For the aim of the study the
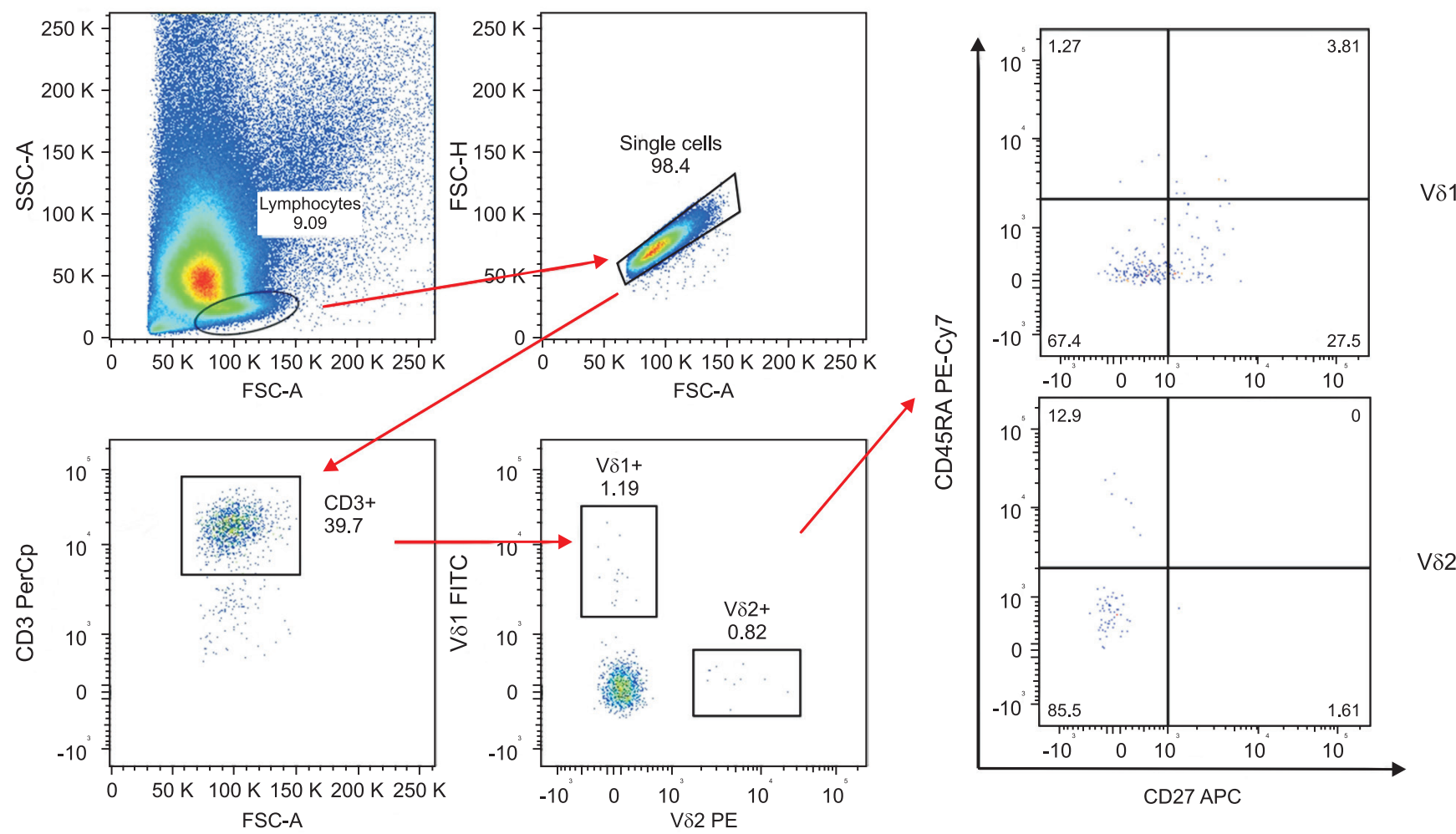

Fig. 1. Gating strategy for flow cytometric analysis of lymphocytes. SSC-A, side scatter area; FSC-A, forward scatter area; FSC-H, forward scatter height; APC, allophycocyanin; PerCp, peridinin chlorophyll protein; FITC, fluorescein isothiocyanate; PE, phycoerythrin.

Table 1. Overall patients' characteristics

\begin{tabular}{lrrrr}
\hline \multicolumn{1}{c}{ Variable } & Total & Healthy & Prostate cancer & p-value \\
\hline Number of patients & $36(100)$ & $16(44.4)$ & $20(55.6)$ & $70.1 \pm 5.5$ \\
Age $(\mathrm{y})$ & $67.2 \pm 7.9$ & $63.6 \pm 9.1$ & $10.3 \pm 3.3$ & \\
Prostate specific antigen $(\mathrm{ng} / \mathrm{mL})$ & $7.7 \pm 3.9$ & $4.5 \pm 1.4$ & & \\
ISUP grade & & - & $13(65.0)$ \\
1 & - & - & $4(20.0)$ \\
2 & - & - & $3(15.0)$ \\
\hline
\end{tabular}

Values are presented as number (\%) or mean \pm standard deviation. 
Table 2. Cancer patients' characteristics stratified according ISUP grade

\begin{tabular}{lcccc}
\hline \multicolumn{1}{c}{ Variable } & Total & ISUP grade 1 & ISUP grade $\geq 2$ & p \\
\hline Number of patients & $20(100)$ & $13(65.0)$ & $7(35.0)$ & \\
Age $(\mathrm{y})$ & $70.1 \pm 5.5$ & $69.4 \pm 5.5$ & $71.4 \pm 5.5$ & 0.439 \\
Prostate specific antigen $(\mathrm{ng} / \mathrm{mL})$ & $10.3 \pm 3.3$ & $10.3 \pm 3.9$ & $10.3 \pm 1.7$ & 0.992 \\
Positive cores & $5.4 \pm 3.1$ & $5.0 \pm 2.9$ & $6.3 \pm 3.5$ & 0.394 \\
\hline
\end{tabular}

Values are presented as number (\%) or mean \pm standard deviation.
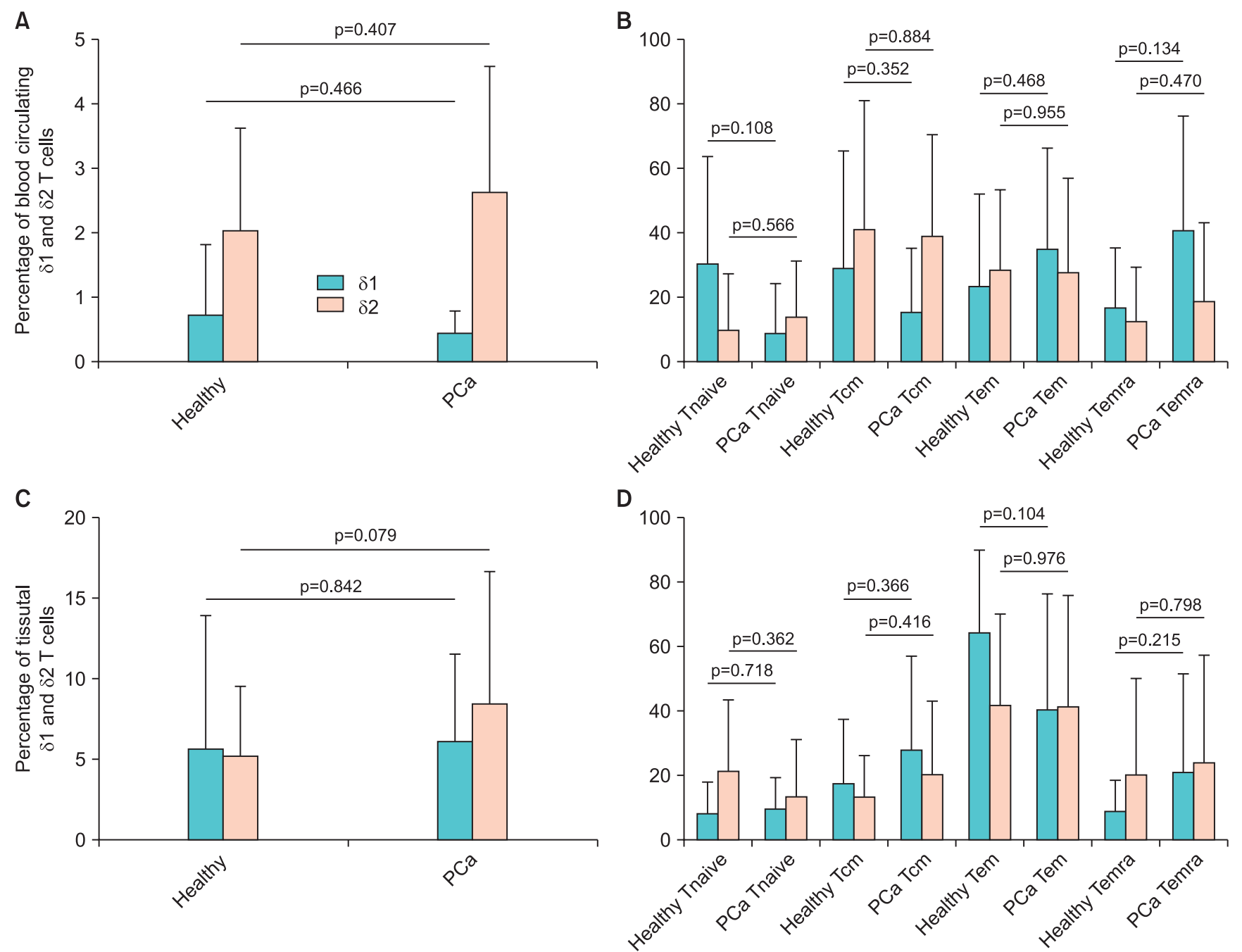

Fig. 2. (A) Percentage of total V $\delta 1$ and V $\delta 2 T$ cells in peripheral blood samples of healthy and prostate cancer (PCa) patients. (B) Distribution of V $\delta 1$ and V $\delta 2 \mathrm{~T}$ cells subsets in peripheral blood samples of healthy and PCa patients. (C) Percentage of total V $\delta 1$ and V $\delta 2 \mathrm{~T}$ cells in prostate biopsy samples of healthy and PCa patients. (D) Distribution of V $\delta 1$ and V $\delta 2 T$ cells subsets in prostate biopsy samples of healthy and PCa patients. Light blue columns identify V $\delta 1$ and pink columns identify V $22 T$ cells. Tnaive, naive T cells; Tcm, central memory T cells; Tem, effector memory T cells; Temra, terminally differentiated T cells. Means were compared through Student t-test: $\mathrm{p}$-values are reported above the corresponding columns.

patients with PIN were excluded. Three patients, one with and two without cancer were excluded because of the lack of data. Thus 36 patients, $20 \mathrm{PCa}$ and 16 healthy patients were included in the analysis. Overall patients' characteristics are shown in Table 1. Within cancer patients, $13(65.0 \%)$ and 7 (35.0\%) men had ISUP grade 1 and $\geq 2$, respectively (Table 2 ).

The $\gamma \delta \mathrm{T}$ cells analysis showed wide variability both on prostate biopsy and PBMC samples. Data showed a slightly higher percentage of $\delta 2 \mathrm{~T}$ cells (2.6\% vs. $2.1 \%)$ and a slightly lower percentage of $\delta 1 \mathrm{~T}$ cells $(0.5 \%$ vs. $0.7 \%)$ in peripheral blood of cancer patients in comparison with healthy patients, although not significant (Fig. 2A). Moreover the analysis of the PBMC samples showed a non-significantly higher percentage of Tem and Temra phenotypes in PCa patients 
(Fig. 2B).

On the contrary, TILs analysis showed a non-significant trend for higher expression of both $\delta 1$ and $\delta 2 \mathrm{~T}$ cells in PCa patients $(6.1 \%$ and $8.5 \%$ vs. $5.7 \%$ and $4.3 \%$ in healthy tissues, respectively) (Fig. 2C).

However, $\delta 2 \mathrm{~T}$ cells obtained from peripheral blood of cancer subjects showed a predominant Tcm phenotype (38.5\%), while the dominant phenotype in the PCa tissue was the Tem phenotype (40.3\%). These results, although not statistically significant, could suggest that the cells committed to effector activities at the tumor site are phenotypically different respect to circulating $\delta 2 \mathrm{~T}$ cell. Nevertheless the phenotypes of $\delta 2 \mathrm{~T}$ cells in healthy and PCa tissue were substantially similar.

Regarding the $\delta 1 \mathrm{~T}$ cells, the most prevalent PBMCs phenotype in PCa patients was Temra (40.7\%), while the most prevalent tissutal phenotype was Tem (38.3\%; Fig. 2B-D). On the contrary the most prevalent phenotypes in PBMCs of healthy subject were Thaive and Tcm. However, also for the V $\delta 1 \mathrm{~T}$ cells, the distribution of the phenotypes in healthy and PCa tissue was substantially similar (not statistically significant).

The percentage of tumor-infiltrating $\gamma \delta \mathrm{T}$ cells according to ISUP grade is shown in the Fig. 3. A non-significant trend was found for lower percentage of infiltrating $\delta 1$ and $\delta 2 \mathrm{~T}$ cell in more aggressive cancer (ISUP grade $\geq 2$ ) in comparison with ISUP grade 1 ( $\mathrm{p}=0.495$ and 0.401 , respectively). However, within the $\mathrm{T}$ cells subsets, the $\delta 2$ Tnaive were significantly more present in the high grade tumors $(p=0.031$; Fig. 3B).

\section{DISCUSSION}

In this study the circulating and tumor infiltrating $\gamma \delta$ $\mathrm{T}$ cells were investigated in patients diagnosed with and without PCa at prostate biopsy. No substantially different percentages of $\gamma \delta \mathrm{T}$ cells were found in peripheral blood and biopsy samples of healthy and PCa patients. A nonsignificant trend for higher expression of both $\delta 1$ and $\delta 2$ $\mathrm{T}$ cells in cancer tissues and for lower expression in more aggressive cancer (ISUP grade $\geq 2$ ) were found in comparison with healthy tissue and ISUP grade 1 cancer, respectively. Moreover we observed a slightly, although not significant, higher percentage of $\delta 2 \mathrm{~T}$ cells and lower percentage of $\delta 1 \mathrm{~T}$ cells in peripheral blood of cancer patients.

Although the effector functions of $\mathrm{a} \beta$ and $\gamma \delta \mathrm{T}$ cells are similar, $\gamma \delta$ TCR binds also tumor-associated ligands in a MHC-independent manner [14], but the exact role of $\gamma \delta \mathrm{T}$ cells is controversial and not well understood yet. Specifically mediating the antigen-specific killing of cancer cells, $\gamma \delta$ $\mathrm{T}$ cells have been associated with improved prognosis in patients with different types of carcinoma, in a retrospective analysis by Gentles et al. [15]. On the contrary some $\gamma \delta \mathrm{T}$ cells subgroups can activate immunosuppressive pathways and angiogenesis, supporting cancer progression. In this case overriding the interferon $\gamma$ mediated antitumor immune response, interleukin (IL)-17 is an important mediator of such protumor functions [9]. IL-17 expression is higher in several human tumors, such as ovarian, cervical cancer, breast cancer, hepatocellular carcinoma, esophageal cancer, gastric and colorectal cancer [14,16]. Interestingly, $\gamma \delta \mathrm{T}$ cells are rare and not recruited nor expanded within renal cell carcinomas
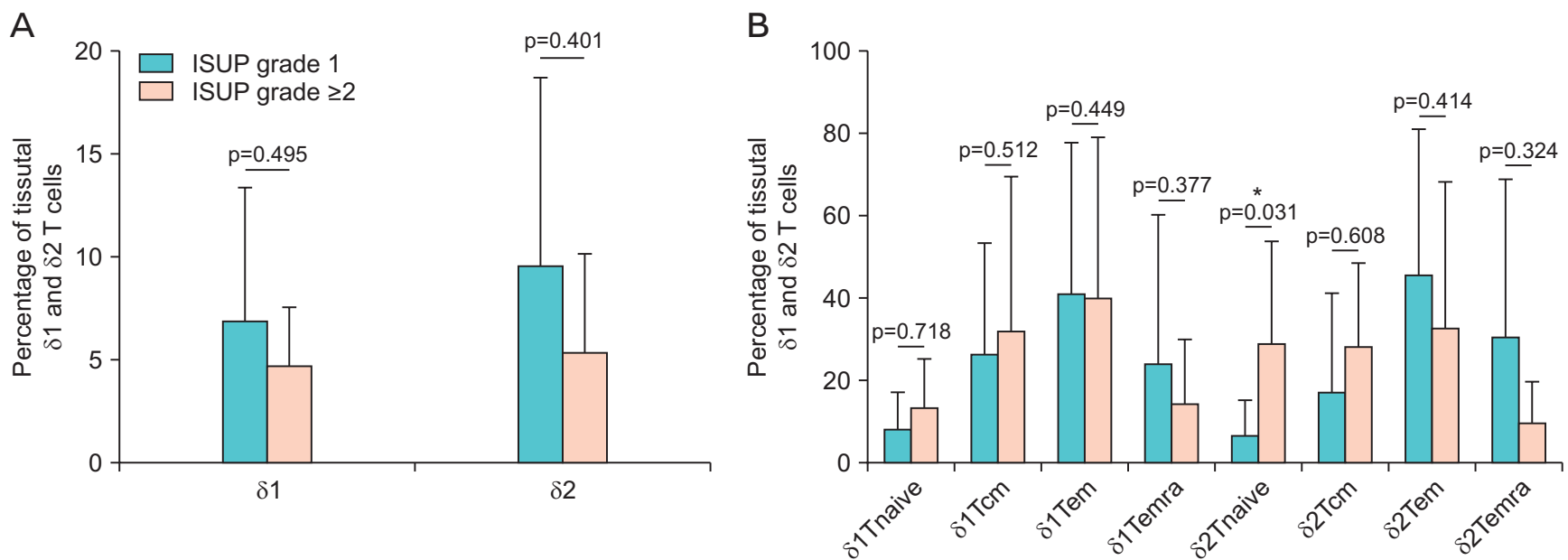

Fig. 3. (A) Percentage of total V $\delta 1$ and V $\delta 2 T$ cells in prostate biopsy samples of prostate cancer (PCa) patients stratified according to ISUP grade (1 vs. $\geq 2$ ). (B) Distribution of V $\delta 1$ and V $\delta 2 \mathrm{~T}$ cells subsets in in prostate biopsy samples of PCa patients stratified according to ISUP grade (1 vs. $\geq 2)$. Light blue columns identify ISUP grade 1 and pink columns identify ISUP grade $\geq 2$. Tnaive, naive T cells; Tcm, central memory T cells; Tem, effector memory T cells; Temra, terminally differentiated T cells. Means were compared through Student t-test: $p$-values are reported above the corresponding columns $\left({ }^{*} p<0.05\right)$. 
and do not correlate with prognostic features nor specific death [17]. On the other hand, intratumoral $\gamma \delta \mathrm{T}$ cells amount was reported to be positively correlated with advanced stages and lymph node metastasis, and thus inversely correlated with both relapse-free and overall survival in breast cancer patients [18]. It is important to note that $\gamma \delta$ T cells secrete $\mathbb{L}-10$ [19] and $\mathbb{L}-17$ [20,21] regulating $\mathrm{CD}{ }^{+} \mathrm{T}$ cell, neutrophils and monocytes recruitment and expansion, initiating the inflammatory response. Such functions could be exploited for immunotherapy; in fact promising results were reported in small-scale applications of $\mathrm{V} \gamma 9 \mathrm{~V} \delta 2 \mathrm{~T}$ cells to hematologic [22] and solid-tissue malignancies, including $\mathrm{PCa}$ and advanced renal cell carcinoma [23]. Moreover recent clinical trials support the use of $\gamma \delta \mathrm{T}$ lymphocytes as immunotherapeutic agents, either via the adoptive transfer of ex vivo expanded $\gamma \delta \mathrm{T}$ cells or following their activation in vivo [24].

The adult prostate contains several endogenous inflammatory infiltrates consisting of a variable amount of $\mathrm{T}$ and B lymphocytes, macrophages and mast cells [3], that may have an important role in cancer pathogenesis (progression or inhibition). T lymphocytes are of ten induced in PCa patients and infiltrate the tumor. In fact $\mathrm{CD}^{+}$and $\mathrm{CD} 4^{+}$ T lymphocytes infiltrates have been shown to be clustered around PCa islets with only few lymphocytes scattered within the tumor area. $\mathrm{CD}^{+}$lymphocytes clusters contain numerous $\mathrm{CD} 25^{+}$and $\mathrm{FOXP}^{+}$cells with regulatory function, inhibiting immune response against cancer cells [25]. Also the $\mathrm{CD}^{+} \mathrm{T}$ cells are recruited into the prostate; however they express high levels of the inhibitory receptor PD-1, indicating exhaustion and inability of mounting an effective immune response [26].

Miller et al. [27] showed that $\mathrm{CD} 4^{+} \mathrm{CD} 25^{+}$regulatory $\mathrm{T}$ cells (Treg) are increased in the tumor tissue and peripheral blood of early-stage PCa patients who had undergone radical prostatectomy compared with benign tissue from the same prostate and peripheral blood of normal donors, concluding that these cells may play a role in modulation of effector $\mathrm{T}$ cell responses against $\mathrm{PCa}$.

Our study demonstrates a non-significant trend for higher expression of both $\delta 1$ and $\delta 2 \mathrm{~T}$ cells in PCa tissue; the majority of PCa-infiltrating V $82 \mathrm{~T}$ cells showed Tem and Temra phenotypes, indicating cells homing to inflammation sites with immediate effector function as cytokine production. Their presence in the context of PCa could suggest a migratory process from the blood or lymphoid tissues, having a role in the immunosurveillance of this tumor. However also the $\gamma \delta \mathrm{T}$ cells found in healthy tissues primarily showed Tem phenotype. Conversely, circulating V82 T from the same patients primarily showed Tcm phenotype that identifies cells homing to secondary lymphoid organs, without immediate effector function. Accordingly Norström et al. [28] reported a greatly different subset composition within lymphocytes isolated from $\mathrm{BPH}$ tissue sampled after trans urethral resection compared to those from peripheral blood, reflecting a different role of the immune system in different bodily environments. In particular both co-inhibitory and co-stimulatory receptors expressing $\mathrm{T}$ cells were described to be more present in $\mathrm{BPH}$ tissue compared to PBMCs, suggesting chronic activation and possible functional exhaustion of TILs. Moreover a recent study reported that the majority of T-cells infiltrating the prostate showed Tem phenotype and those from PCa tissue could be on average 20-fold higher than that obtained from controls (BPH and normal prostates); on the other hand Treg cells did not seem to be unique to the PCa setting, but they were frequently found in the prostate gland compared to peripheral blood regardless of prostate condition, again indicating a role in prostate homeostasis [29].

Finally it is noteworthy that in our population lower, although not significant, levels of infiltrating $\gamma \delta \mathrm{T}$ cells were found in more aggressive PCa (ISUP grade $\geq 2$ ). Similarly, in a previous study reporting a higher percentage of Treg and T helper (Th) 17 CD4 ${ }^{+}$TILs in PCa tissue, a different T cells phenotype distribution was associated with $\mathrm{PCa}$ grade; in particular a preponderant Th17-mediated inflammation was associated with lower Gleason score [30].

If confirmed in larger studies, this could be important as the Gleason score is an independent prognostic factor of $\mathrm{PCa}$ and in many cases can guide the therapeutic choice (surveillance vs. active treatment) [1]

This small prospective study still cannot give answers on the potential independent prognostic value of the $\gamma \delta \mathrm{T}$ cells isolation on $\mathrm{PCa}$ bioptic specimens. One limitation could be that the TILs analyses were performed on two additional biopsy cores, without the certainty that the tissues sampled would be the same of the diagnostic ones (12 cores sextant biopsy). However it is known that the prostate tissue is highly variable and $\mathrm{PCa}$ is typically multifocal, unilateral or bilateral. According to this and the typical distribution of the TILs infiltrate already described in literature [25], we considered appropriate the analysis of the additional cores almost near to the positive ones. Moreover we considered as healthy those patients without cancer at biopsy, including those with normal histological findings and $\mathrm{BPH}$; all the patients presented focal signs of inflammatory response at pathological examination, as usual in clinical practice.

This is the first report of the $\gamma \delta \mathrm{T}$ cells isolation on 
prostate biopsy specimen in relation to $\mathrm{PCa}$ diagnosis and ISUP grade in a cohort of subjects with homogenous clinical characteristic (age and prostate specific antigen values). Future studies should focus on the role of $\gamma \delta \mathrm{T}$ cells in $\mathrm{PCa}$ progression, but also in pre-malignant conditions as PIN.

\section{CONCLUSIONS}

The study of tumor infiltrating lymphocytes subpopulation is feasible in prostate biopsy samples. No substantially different percentages of $\gamma \delta \mathrm{T}$ cells were found in peripheral blood and biopsy samples of healthy and $\mathrm{PCa}$ patients. However a non-significant trend for lower infiltrate in higher grade cancer (ISUP grade $\geq 2$ ) was observed. $\gamma \delta \mathrm{T}$ cells might have a central role in this context but we are still far from their clinical use. In fact the exact role of $\mathrm{T}$ cells in immunosurveillance and in tumor progression, particularly in relation to specific cytokines production, needs better understanding.

\section{CONFLICTS OF INTEREST}

The authors have nothing to disclose.

\section{ACKNOWLEDGMENTS}

Dr. Daniela Coniglio received a grant from the University of Palermo for her international Immunopharmacology $\mathrm{PhD}$ project entitled "Characterization of Human $\gamma \delta \mathrm{T}$ Cells Infiltrating Prostate Cancer."

\section{REFERENCES}

1. Albertsen PC, Hanley JA, Fine J. 20-year outcomes following conservative management of clinically localized prostate cancer. JAMA 2005;293:2095-101.

2. Thompson IM, Goodman PJ, Tangen CM, Lucia MS, Miller GJ, Ford LG, et al. The influence of finasteride on the development of prostate cancer. N Engl J Med 2003;349:215-24.

3. De Marzo AM, Platz EA, Sutcliffe S, Xu J, Grönberg H, Drake CG, et al. Inflammation in prostate carcinogenesis. Nat Rev Cancer 2007;7:256-69.

4. Hao J, Wu X, Xia S, Li Z, Wen T, Zhao N, et al. Current progress in $\gamma \delta$ T-cell biology. Cell Mol Immunol 2010;7:409-13.

5. Dieli F, Gebbia N, Poccia F, Caccamo N, Montesano C, Fulfaro $\mathrm{F}$, et al. Induction of gammadelta T-lymphocyte effector functions by bisphosphonate zoledronic acid in cancer patients in vivo. Blood 2003;102:2310-1.

6. Moser B, Eberl M. $\gamma \delta$ T-APCs: a novel tool for immunothera- py? Cell Mol Life Sci 2011;68:2443-52.

7. Tyler CJ, McCarthy NE, Lindsay JO, Stagg AJ, Moser B, Eberl M. Antigen-presenting human $\gamma \delta$ T cells promote intestinal CD4+ T cell expression of IL-22 and mucosal release of calprotectin. J Immunol 2017;198:3417-25.

8. Mangan BA, Dunne MR, O'Reilly VP, Dunne PJ, Exley MA, O'Shea D, et al. Cutting edge: CD1d restriction and Th1/Th2/ Th17 cytokine secretion by human V $\delta 3 \mathrm{~T}$ cells. J Immunol 2013;191:30-4.

9. Rei M, Pennington DJ, Silva-Santos B. The emerging protumor role of $\gamma \delta$ T lymphocytes: implications for cancer immunotherapy. Cancer Res 2015;75:798-802.

10. Urban EM, Chapoval AI, Pauza CD. Repertoire development and the control of cytotoxic/effector function in human gammadelta T cells. Clin Dev Immunol 2010;2010:732893.

11. Dieli F, Poccia F, Lipp M, Sireci G, Caccamo N, Di Sano C, et al. Differentiation of effector/memory Vdelta2 $\mathrm{T}$ cells and migratory routes in lymph nodes or inflammatory sites. J Exp Med 2003;198:391-7.

12. Jensen KD, Chien YH. Thymic maturation determines gammadelta $\mathrm{T}$ cell function, but not their antigen specificities. Curr Opin Immunol 2009;21:140-5.

13. Tortorici S, Argo A, Buzzanca ML, Burruano F, Tetè S. Information, consent and therapeutic alliance in ambulatorial oral surgery. Ital Oral Surg 2009;8:155-64.

14. Rei M, Gonçalves-Sousa N, Lança T, Thompson RG, Mensurado S, Balkwill FR, et al. Murine CD27(-) V $\gamma 6(+) \gamma \delta \mathrm{T}$ cells producing IL-17A promote ovarian cancer growth via mobilization of protumor small peritoneal macrophages. Proc Natl Acad Sci U S A 2014;111:E3562-70.

15. Gentles AJ, Newman AM, Liu CL, Bratman SV, Feng W, Kim $\mathrm{D}$, et al. The prognostic landscape of genes and infiltrating immune cells across human cancers. Nat Med 2015;21:938-45.

16. Ma S, Cheng Q, Cai Y, Gong H, Wu Y, Yu X, et al. IL-17A produced by $\gamma \delta \mathrm{T}$ cells promotes tumor growth in hepatocellular carcinoma. Cancer Res 2014;74:1969-82.

17. Inman BA, Frigola X, Harris KJ, Kuntz SM, Lohse CM, Leibovich $\mathrm{BC}$, et al. Questionable relevance of gamma delta T lymphocytes in renal cell carcinoma. J Immunol 2008;180:3578-84.

18. Ma C, Zhang Q, Ye J, Wang F, Zhang Y, Wevers E, et al. Tumorinfiltrating $\gamma \delta \mathrm{T}$ lymphocytes predict clinical outcome in human breast cancer. J Immunol 2012;189:5029-36.

19. Rhodes KA, Andrew EM, Newton DJ, Tramonti D, Carding SR. A subset of IL-10-producing gammadelta $\mathrm{T}$ cells protect the liver from Listeria-elicited, CD8(+) T cell-mediated injury. Eur J Immunol 2008;38:2274-83.

20. Jensen KD, Su X, Shin S, Li L, Youssef S, Yamasaki S, et al. Thymic selection determines gammadelta $\mathrm{T}$ cell effector fate: antigen-naive cells make interleukin-17 and antigen-experienced 
cells make interferon gamma. Immunity 2008;29:90-100.

21. Wu X, Zhang JY, Huang A, Li YY, Zhang S, Wei J, et al. Decreased $\mathrm{V} \delta 2 \gamma \delta \mathrm{T}$ cells associated with liver damage by regulation of Th17 response in patients with chronic hepatitis B. J Infect Dis 2013;208:1294-304.

22. Wilhelm M, Kunzmann V, Eckstein S, Reimer P, Weissinger F, Ruediger T, et al. Gammadelta T cells for immune therapy of patients with lymphoid malignancies. Blood 2003;102:200-6.

23. Kobayashi H, Tanaka Y, Yagi J, Osaka Y, Nakazawa H, Uchiyama $\mathrm{T}$, et al. Safety profile and anti-tumor effects of adoptive immunotherapy using gamma-delta $\mathrm{T}$ cells against advanced renal cell carcinoma: a pilot study. Cancer Immunol Immunother 2007;56:469-76.

24. Guo RT, Cao R, Liang PH, Ko TP, Chang TH, Hudock MP, et al. Bisphosphonates target multiple sites in both cis- and transprenyltransferases. Proc Natl Acad Sci U S A 2007;104:100227.

25. Ebelt K, Babaryka G, Frankenberger B, Stief CG, Eisenmenger W, Kirchner T, et al. Prostate cancer lesions are surrounded by FOXP3+, PD-1+ and B7-H1+ lymphocyte clusters. Eur J Cancer 2009;45:1664-72.
26. Sfanos KS, Bruno TC, Meeker AK, De Marzo AM, Isaacs WB, Drake CG. Human prostate-infiltrating CD8+ T lymphocytes are oligoclonal and PD-1+. Prostate 2009;69:1694-703.

27. Miller AM, Lundberg K, Ozenci V, Banham AH, Hellström M, Egevad L, et al. CD4+CD25high T cells are enriched in the tumor and peripheral blood of prostate cancer patients. J Immunol 2006;177:7398-405.

28. Norström MM, Rådestad E, Sundberg B, Mattsson J, Henningsohn L, Levitsky V, et al. Progression of benign prostatic hyperplasia is associated with pro-inflammatory mediators and chronic activation of prostate-infiltrating lymphocytes. Oncotarget 2016;7:23581-93.

29. Rådestad E, Egevad L, Jorns C, Mattsson J, Sundberg B, Nava $S$, et al. Characterization of infiltrating lymphocytes in human benign and malignant prostate tissue. Oncotarget 2017;8:60257-69.

30. Sfanos KS, Bruno TC, Maris CH, Xu L, Thoburn CJ, DeMarzo $\mathrm{AM}$, et al. Phenotypic analysis of prostate-infiltrating lymphocytes reveals TH17 and Treg skewing. Clin Cancer Res 2008;14:3254-61. 